\section{Carl Schmitt, teologia politica e secularização}

Pedro Villas Bôas Castelo Branco. Secularização inacabada: politica e direito em Carl Schmitt. Curitiba, Appris, 2011. 309 páginas.

\section{Cicero Araujo}

O leitor encontrará neste livro de Pedro Villas Bôas uma excelente exposição do pensamento político do jurista alemão Carl Schmitt. De fato, um livro que, em seu entusiasmo e complexidade, vai além da exposição: fruto de uma premiada tese de doutorado, seu autor oferece uma leitura muito original, em certos aspectos desconcertante, da obra de Schmitt.

Como indica o título, a chave interpretativa do livro é o conceito de secularização, pano de fundo indispensável, afirma o autor, das controvertidas visões do jurista sobre a política de seu tempo e sobre a natureza do direito e da política de um modo geral. Para apurar essa chave, o livro abrange os escritos de juventude de Schmitt, ainda pouco destacados pela crítica, e analisa com bastante cuidado duas obras em particular: Gesetz und Urteil (traduzido como Lei e julgamento), de 1912, e Der Wert des Staates und die Bedeutung des Einzelnen $(O$ valor do Estado e o significado do individuo), publicado em 1914. Villas Bôas dedica dois longos capítulos para discuti-las, mostrando suas ligações com outros momentos da obra schmittiana e inquirindo a literatura secundária - em particular, como seria natural, a produzida na Alemanha. Ademais, graças a um trabalho de garimpagem exemplar, feito na biblioteca e nos arquivos pessoais de Schmitt (guardados em Düsseldorf), o autor reforçou sua própria interpretação com remissões à sua riquíssima correspondência e a obras de outros pensadores consultados ou anotados pelo jurista.

Após elaborar os ganhos que esses escritos de juventude propiciam ao conceito de secularização, o livro passa a projetá-los sobre o pensamento maduro de Schmitt, no terceiro e último capítulo, apontando uma derradeira variação do significado do termo, agora iluminada pelo percurso anterior. Neste capítulo encontram-se também seus argumentos mais incisivos sobre a atualidade das concepções schmittianas de soberania, Estado, a especificidade do político, o direito internacional e sua crítica do liberalismo. Independentemente do desconcerto que, às vezes, essa parte do livro possa produzir no leitor, o resultado geral do trabalho é elucidativo e, na certa, o estudioso da teoria política termina sua leitura com uma compreensão mais profunda não só da intrincada malha conceitual tecida pelo autor alemão, mas também de alguns dos grandes problemas contemporâneos da política e do direito.

Ao contrário de muitos de seus colegas de profissão, Schmitt não costumava escrever textos longos e era um tanto avesso à sistematização. Preferia intervençōes bastante compactas para enfrentar questões teóricas que pareciam as mais salientes na ocasião da escrita. Ao estudioso do conjunto da obra, no entanto, não faltará a percepção de continuidades, insistências sobre um mesmo leque de temas, mas com variações importantes. $\mathrm{Na}$ visão do autor aqui resenhado, a secularização é um desses temas que persistem em sua obra do começo ao fim. Mas também como um ponto problemático porque, na pena do jurista, o conceito oscila entre a orientação cognitiva e - se Villas Bôas estiver certo - algo como uma meta prática. Nesse último sentido, a secularização aparece como o horizonte de uma ação política tida como a mais adequada, todavia não alcançado em seu tempo, quiçá jamais inteiramente alcançável. Daí a palavra que complementa o título do livro: a "secularização inacabada".

Antes de fazer algumas notas críticas a seu empreendimento - e explicar o que, afinal, enxergo de desconcertante nele - resumirei, na medida do possível, que contribuições à semântica da secularização o autor vislumbra na obra de Schmitt.

\section{Secularização e direito}

Geralmente associamos a palavra "secularização" com o gradual afastamento das sociedades modernas de sua dependência, em todas as dimensôes da vida, para com a religião cristã. Porém, a primeira contribuição do jurista não remete especificamente à questão religiosa, mas ao problema da viabilização política e prática da "ideia do direito". Por cer- 
to, há nesse significado um paralelismo formal com um velho problema teológico, que o uso da palavra indica de propósito: o problema da mediação entre um ser ou elemento transcendente e o mundo (saeculum). Ao empregá-la nas obras de juventude - segundo Villas Bôas, de modo implícito no livro de 1912 e explicitamente no de 1914 - Schmitt estava concentrado nos debates em torno das teorias do direito da época e especialmente na crítica ao positivismo jurídico. Nesse caso, o elemento transcendente não é o Deus cristão, mas a própria ideia do direito, condenada a permanecer uma simples ideia enquanto não encontrasse um modo de se vincar ao mundo. Trata-se, então, do problema de mediar entre dois polos, dois "universos" em princípio inteiramente separados, o transcendente e o imanente. Este seria o ponto crucial da secularização na esfera do direito, para o qual a forma política (Estado) aparece como resposta: "o direito não pode querer realizar-se a partir de si mesmo [...]", afirma Schmitt em 1914; “o direito é pensamento abstrato que não pode ser derivado de fatos, tampouco agir sobre fatos; o sujeito de uma vontade voltada para a realização do direito só pode ser uma realidade" (citado por Villas Bôas, pp.163-164).

Ao resgatar essa contribuição semântica, o autor nos esclarece duas coisas. Primeiro, as motivações schmittianas que o afastavam do positivismo jurídico tanto na pretensão, por um lado, de reduzir o direito a um fato do mundo, quanto na expectativa, por outro, de reduzir a política do Estado ao chamado "governo da lei", eliminando o máximo possível os traços de subjetividade e arbítrio. Em segundo lugar, ele consegue mostrar muito bem a importância que a noção de "contingência" tem no pensamento do jurista, na medida em que ela suscita o quadro conceitual que estrutura não só sua concepção do direito, mas sua teoria política como um todo. Pois é precisamente a questão da contingência que revelaria a visão dualista de Schmitt, pela qual recusa qualquer pressuposto de uma relação causal entre a materialidade do mundo e a ideia do direito. Há entre uma e outra uma decalagem essencial, que só pode ser transposta, e ainda assim parcialmente, pela intervenção política, com tudo que há de especificamente humano nela: a intenção, a vontade, o juízo - enfim, a subjetividade. Eis sua anotação precisa: "Para Schmitt a ideia jamais encarna plenamente, ou não é transferida na sua totalidade à realidade [...] a transposição de um ideal para o plano real resulta sempre em algo diferente da ideia originária” (p. 172, nota 93).

Com essa leitura, luzes são projetadas sobre conceitos tão caros a Schmitt, como o de "soberania”, e seus vínculos internos com o de "decisão". Mas na sequência da análise, vão se iluminando ainda outros mais, e que orientarão Villas Bôas no arremate que fará no capítulo final do livro: é que a contingência explica por que Schmitt tem de falar do ato de soberania não só como decisão, mas também como "exceção" e "representação". Dar realidade efetiva ao direito não é simplesmente aplicar, como numa subsunção, uma norma ou conjunto de normas ao caso, sejam essas normas não escritas (como as expressas na ideia de "lei natural"), sejam escritas, mas aceitar, pela mediação humana - daí o sentido da representação - o elemento contingente dos acontecimentos do mundo, que nenhuma lei é capaz de apreender inteiramente. De modo que o autêntico ato de decidir, mesmo quando se trata de atividade rotineira do juiz, implica atritos com a norma, no limite uma ruptura, vale dizer, uma quebra da norma. Mais ampla e significativamente, o fundamental da soberania não é a legalidade em si, como se essa tivesse o dom de determinar toda e qualquer decisão política subsequente, mas, ao contrário, todos aqueles gestos humanos que, precedendo a legalidade, também a visa. Contudo, a exceção não só precede a norma, mas, sendo uma ruptura, a esclarece - assim como esclarece a normalidade em geral: "Somente a conscientização do dualismo inerente ao mundo do ser torna inteligível a contingência. Consequentemente, a ideia somente se faz visível na contingência, ruptura, crise, enquanto na continuidade direta ou em concepções imediatistas, com a qual opera a visão positivista, identificam-se [confundem-se?] ideias e fatos, direito e poder, ciência e vida" (p. 106).

Expressão de uma "crise", a decisão dá visibilidade à ideia do direito, que de outro modo - isto é, sem se distinguir do poder - permaneceria invisível e, como tal, irrepresentável por pessoas e instituições. Quer dizer, invisível, a ideia resta indiferente à secularização. 


\section{As dimensóes da secularização}

Duas outras contribuiçōes semânticas aparecem no pensamento posterior de Schmitt, trazendo uma virada importante em relação à primeira, complementando-a, segundo Villas Bôas. Nelas, a secularização surge como um processo histórico próprio à modernidade e, simultaneamente, como uma ferramenta heurística ("hermenêutica") que permite esclarecer a "imagem metafísica" que uma época faz de si mesma. Como processo histórico, a secularização se inicia com a passagem da "era da teologia" (século XVI) para a "era da metafísica" (século XVII), na qual, em termos políticos, se afirma o absolutismo. Este último, porém, é apenas a chave desencadeadora do processo, pois a secularização avança em novos deslocamentos: da "era da metafísica" para a "era do humanismo e da moral" e dessa para a "era da economia" e da "técnica" (século XIX e nossa época). Note-se que a qualificação de cada era já traduz o sentido hermenêutico da secularização ao apontar o "núcleo" das suposições espirituais - a "imagem metafísica" - dessa época. Para Schmitt, identificar esse "núcleo" é politicamente relevante, pois permite esclarecer de que modo uma determinada época viabiliza um "terreno neutro" em relação aos conflitos que a marcam. Por isso mesmo, esse terreno é também seu "último ponto de legitimidade". Assim, numa era marcada pelos conflitos religiosos, o próprio Estado absolutista vai se colocar nesse papel. A partir daí, cada novo deslocamento passará a substituir "imagens de transcendência" por "imagens de imanência" - a moral, a economia, a técnica - que, por sua vez, diz o que a época correspondente assume para si como espaço neutro e seu fundamento de legitimidade. Eis a síntese que faz nosso autor dessa elaboração:

A secularização consiste numa substituição de imagens cuja dissolução de representaçōes tradicionais não implica a eliminação de um fundamento metafísico. De um lado, o surgimento do Estado moderno e seus conceitos jurídicos e políticos resultam de um processo de secularização compreendido a partir da neutralização dos conflitos religiosos dos séculos XVI e XVII. De outro, a secularização é apresentada como sucessiva substituição de imagens metafísicas [...]. Desse ponto de vista, a estrutura ontológica da realidade é formada pelas representaçōes do mundo que ocupam uma posição central. Posto de outra forma: as qualidades da realidade são conformadas pelas projeçōes de crenças que alcançam um lugar central, ou "ponto último de legitimidade", para suas representaçôes (p. 213).

Schmitt usa "secularização" nesse duplo sentido (histórico e hermenêutico) já em Romantismo político (1919) e retoma-o em obras posteriores, notadamente em Teologia politica (publicada pela primeira vez em 1922), mas também em comentários adicionais a essa obra - reeditada com um novo prefácio em 1934 - e ao seu $O$ conceito do politico, publicado em 1927, no final do qual acrescenta, na segunda edição (de 1932), o texto de uma conferência realizada entre uma edição e outra, onde o nexo entre secularização, neutralização $\mathrm{e}$ legitimidade surge como tópico central. Também vamos encontrar novos esforços de esclarecimento de sua posição nos debates sobre filosofia da história em que se envolve ao longo das décadas de 1950 e 1960, em particular com os filósofos alemães Karl Löwith e Hans Blumenberg - autores que se tornarão, na literatura acadêmica internacional, referências inescapáveis do assunto. Pedro Villas Bôas examina cada um desses desdobramentos da visão de Schmitt, detendo-se nas passagens relevantes dos textos e enfrentando as dificuldades de interpretação, num cerrado diálogo com a literatura secundária. Muito fina, aliás, é a análise do debate entre Schmitt e Blumenberg, do qual se beneficia para marcar a evolução do próprio jurista a respeito de como caracterizar a secularização como um processo histórico (cf. pp. 211-226).

Porém, o que interessa mais ao cerne de seu empreendimento é a leitura que o faz propor uma chave que uniria os dois textos que, talvez mais do que quaisquer outros, marcam a obra do jurista, isto é, a Teologia politica e $O$ conceito do político. Pontuados por fórmulas curtas e densas, são textos em que Schmitt emprega, mais do que o usual, um estilo aforístico e até certo ponto enigmático, que prende a atenção do leitor, porém, ao mesmo 
tempo, deixa-o imaginar o que mais aquelas fórmulas poderiam estar dizendo. Não por acaso é desses livros que saem as passagens que lapidaram o pensamento schmittiano e o tornaram universalmente conhecido: aquela que associa, no primeiro livro, o conceito de soberania com o de exceção - o soberano é "aquele que decide sobre a exceção" - e o que aproxima, no segundo, o conceito "do político" não a uma coisa, mas a uma relação humana específica, ou melhor, uma distinção: "A específica distinção política em que os motivos e ações políticos podem ser reduzidos é aquela entre amigo e inimigo".

Embora o tempo que separa os dois livrinhos seja breve, é curioso que Schmitt não tenha elaborado sistematicamente um vínculo entre as ideias expostas em ambos, o que deixa muito a pensar. É óbvio que essa questão não é nova entre os estudiosos, mas Villas Bôas sugere que a chave esteja justamente no tema que seu livro aborda. $\mathrm{O}$ ponto de ligação de sua leitura é outra fórmula de Teologia política, na qual Schmitt propõe que "todos os conceitos significativos da teoria moderna do Estado são conceitos teológicos secularizados”. Alguns dos estudiosos hoje mais influentes da obra tomam essa passagem para revelar uma trama conceitual que vincula sistematicamente a visão schmittiana com suas crenças religiosas, vale dizer, o catolicismo: seu pensamento nada mais seria do que a derivação política de uma teologia católica. Villas Bôas insurge-se contra essa interpretação, para mostrar que o importante não é o conteúdo religioso, mas a orientação metodológica que inspira Schmitt a apontar, por analogia, semelhanças formais entre a teologia cristã e a teoria moderna do Estado. A chamada "teologia política" do jurista, expressão que o próprio autor aqui resenhado não recusa, não é uma questão de doutrina, mas de heurística, isto é, uma ferramenta para deslindar as liçôes mais relevantes da teoria política moderna. $\mathrm{E}$ o que de fato chama a atenção de Villas Bôas não é a teologia em si, mas a relação que Schmitt sugere entre teologia e secularização. Daí a analogia que o faz explorar conceitualmente as proximidades formais da ideia do Deus-legislador, da teologia cristã, com a de legislador humano - o soberano - da teoria do Estado, ou da ideia de milagre com a de exceção, e assim por diante. Nosso autor reco- lhe todas essas passagens para ligá-las à sua leitura anterior dos textos de juventude, cujo resultado líquido é precisamente relacionar a secularização com o problema da contingência. Assim, o soberano-legislador, que, porém, dá a lei a partir de um ato de exceção, é o modo pelo qual a teoria do Estado lida com a contingência. Sendo um termo irredutível da própria ação política, a contingência também traz à tona o sentido de secularização que Schmitt mais quer resgatar. Ou seja, a secularização entendida como o problema da distância entre o transcendente e o imanente, do lapso entre a ideia abstrata e a vida humana concreta: a contingência torna visível essa quebra e, ao mesmo tempo, expõe a necessidade de uma figura humana que busque emendá-la. O soberano é essa figura e, por isso mesmo, "encarna” a exceção.

Mas o autor vai além. Resgatando o sentido histórico da secularização, ele mostra como, através do conceito de exceção, Schmitt ataca as "imagens de imanência” que caracterizam a nossa época e os efeitos despolitizadores que produzem no pensamento de um modo geral, mas especialmente no jurídico. Tal como elas produzem a concepção de um mundo natural totalmente regido por causas mecânicas, livre, portanto, do milagre a intervenção divina no mundo -, seu correlato político e jurídico é o mundo humano totalmente regido por normas e, assim, livre da exceção, tornando o próprio conceito de soberania inútil. Essa visão, tão presente no legalismo que marca as teorias jurídicas positivistas atacadas por Schmitt, denuncia o esforço da época para extirpar a contingência de todas as esferas da vida - na verdade, um esforço vão, nada além de um encobrimento, pois, mesmo que se pudesse fazê-lo no mundo natural, isso seria impossível na vida humana: neste âmbito, a contingência é tão inevitável quanto a política é imprescindível. E, porém, é o próprio pensamento contemporâneo que se revolta contra esse fato, em particular quando dá relevo ao papel da economia e da técnica na busca de "automatizar" as relações sociais: "A secularização revelaria uma sucessão de representaçóes de imanência manifestadas por meio de noçôes como autogoverno, autofuncionamento, autorregulamentação [...]. Nas representações de imanência as ações políticas 
são inócuas, pois o mundo político, social e econômico funciona por si mesmo, possui um motor próprio". Como diz Schmitt, nada precisaria ser governado "quando se abandona o mecanismo do econômico e do técnico a sua regularidade imanente" (p. 215).

\section{Algumas notas de desconcerto}

E o que dizer da ligação entre os conceitos de soberania e exceção, apresentados em Teologia política, e a distinção amigo/inimigo, de $O$ conceito do político? Esse é o ponto que oferece as maiores dificuldades para a leitura de Villas Bôas, pois não fica claro como a distinção amigo/inimigo dialoga com a distinção entre o transcendente e o imanente que, além da exceção, marca o problema da secularização. $\mathrm{O}$ próprio autor percebe essa dificuldade e, quando passa a lidar com $O$ conceito do político, trata de fazer o registro de outra variação importante no sentido schmittiano de secularização: "No capítulo anterior [em que uma das obras de juventude está sob exame], a secularização buscava evidenciar a dimensão contingencial da realidade fática, evidenciando a decisão política pela realização de um ideal. Agora, não se trata de expor a tensão entre ser e dever[-ser], mas a virtualidade do ser ou não ser das coletividades humanas" (p. 249). Essa observação busca sintonizar-se com o esforço, em Schmitt, de encontrar a distinção especificamente política, isto é, aquela que diferenciaria "o político" do moral-normativo (o certo e o errado), do jurídico-normativo (o legal e o ilegal), do econômico etc. Por isso a distinção entre ideal (o dever-ser) e real (o ser) é substituída, agora, por uma distinção simplesmente existencial: em termos práticos, a distinção amigo/inimigo é, no fundo, o problema da afirmação da existência de um ser (uma comunidade humana) contra a de outro ser de mesma natureza. Parece então que nessa passagem ficamos reduzidos a um elemento puramente imanente (existencial), embora ainda assim contingente, pois não está fadado que duas (ou mais) comunidades humanas estejam sempre colocadas numa relação de amigo/inimigo. Onde estaria, nesse quadro, o elemento transcendente?
Numa nota de rodapé, Villas Bôas faz a seguinte tentativa: "O caráter transcendente do político revela-se no fato dos antagonismos existenciais (dimensão do político) não poderem ser subordinados a nenhum conjunto de regras, sejam elas morais, jurídicas ou econômicas. O político transcende a qualquer normatização" (p. 216, nota 120). Convenhamos que, aqui, o autor estende para além do razoável o significado de uma palavra... Mas não é nesse ponto que Villas Bôas fixa sua análise que, de resto, permanece num rodapé. A resposta fundamental, na verdade, desloca-se para outro lugar, que porém preserva ao menos um aspecto da secularização, o hermenêutico, já destacado anteriormente. É que a distinção amigo/inimigo "esclarece" ou "torna visível" aquilo que normalmente permanece oculto - precisamente o status especial "do político”. Noutras palavras, esclarecer, tornar visível, é ser capaz de fazer a distinção fundamental - a distinção política. Observe-se, no entanto, que tal distinção não corresponde a qualquer tipo de conflito humano, desses que ocorrem rotineiramente entre indivíduos e grupos, sejam eles vazados em termos religiosos, morais, econômicos etc. Schmitt chama a atenção, e nosso intérprete está atento a isso, que não é o conteúdo do conflito que caracteriza o político, mas sim o seu grau ou intensidade. Sua peculiaridade só se torna visível quando o conflito atinge um grau extremo - vale dizer, o grau em que a própria existência, não de um indivíduo, mas de uma comunidade humana, é posta em questão. Nesse sentido, qualquer conflito, independentemente de seu conteúdo, pode atingir a intensidade do político. De toda maneira, é apenas numa situação crítica, a mais crítica possível - como ocorre numa guerra -, que o especificamente político se faz patente. Essa, porém, não é a situação normal, rotineira ou constante, da vida de uma comunidade. Pelo contrário, trata-se de ruptura, de quebra da normalidade - eis a exceção outra vez, posta de outra forma - e que expõe toda a contingência da vida humana ao colocá-la perante seu exato oposto (o inimigo e a morte). É importante notar, porém, que a essa situação não se chega por um processo espontâneo, como se estivesse inscrita na natureza das coisas, mas sempre por uma decisão humana, representativa de uma comunidade. É assim que "o 
político" torna límpido e cristalino, mas também inescapável, o conceito de um soberano: pois este que "decide sobre a exceção" decide também, e acima de tudo, sobre "quem é o inimigo".

A partir dessa passagem, a análise de Pedro Villas Bôas ganha um novo tom. Quero dizer, desde esse ponto, o autor passa não só a indicar as ricas decorrências que Schmitt, orientado pelo sentido hermenêutico da secularização, extrai do conceito do político, mas também a mostrar sua enorme atualidade. É que nosso autor, numa atitude pouco comum entre intérpretes acadêmicos, não esconde sua convergência básica com a perspectiva do jurista alemão, compartilhando com ele as preocupaçôes com as consequências, eventualmente nefastas, da despolitização, que pensa ser não só do tempo em que Schmitt escreveu suas teses fundamentais, porém, até mais ainda, de nosso tempo. Essa despolitização se traduz no esforço que faz uma época de ocultar a possibilidade do conflito extremo e, nessa tentativa vã, por mais paradoxal que isso pareça, levar os homens a seguirem além dessa possibilidade, desembocando na realidade mesma da autodestruição. Isto é, Villas Bôas vê em Schmitt - mais nas entrelinhas, é preciso dizer, do que propriamente nas linhas - o autor desta grande advertência: careceria reconhecer aquela possibilidade, para que se pudesse submeter o próprio conflito a um controle razoável. Como a secularização significa, em sua dimensão hermenêutica, o processo que nos tornaria capazes de fazer a distinção fundamental e assim manter visível o político, sua conclusão é que continuamos longe dessa meta, persistindo numa época pouco secularizada, ou ao menos aquém do necessário para preservar a coexistência de distintas comunidades humanas.

Sem conseguir fazer jus, nesse espaço, a todas as fascinantes articulações do livro, aponto, em breves linhas finais, o que enxergo de desconcertante nele. $\mathrm{O}$ primeiro motivo do desconcerto, e o mais importante do ponto de vista estritamente analítico, é o modo como o autor acaba privilegiando o sentido hermenêutico ao sentido histórico da secularização. Villas Bôas faz esse deslocamento secundarizando a oposição entre ambos os sentidos, o que, enfim, até poderia explicar por que aquele deslocamento se tornou necessário em sua análise.
Lembremos que em Schmitt a secularização, entendida como um processo histórico, começa com a afirmação do Estado absolutista, que submete a si o poder espiritual da igreja, mas prossegue na direção de sucessivas épocas, marcadas agora por "imagens de imanência", até culminar na "era da técnica", que é a mais despolitizada possível. Ora, se a secularização significasse isso, ela não poderia servir como gume crítico de nossa época - como pretende o sentido hermenêutico -, mas, ao contrário, seria sua simples confirmação: é verdade que a secularização histórica possibilita, de início, o Estado soberano, mas seu último desdobramento é a era da técnica, que afinal representa - mais até do que a era da economia - a negação do cerne do Estado, o conceito de soberania.

Talvez por isso o autor diga, em certo momento do livro, mas de novo contornando a oposição mostrada aqui, que "Schmitt intenta reabilitar o sentido de secularização conquistado pelo Estado moderno europeu do século XVII" (p. 292) - vale dizer, da época que é anterior ao prevalecimento das "imagens de imanência" que marcam as eras subsequentes. É como se dissesse o seguinte: Schmitt gostaria que a secularização se encerrasse ali. Porém, a própria maneira schmittiana de projetar a secularização como processo histórico leva-o a apontar sua continuidade. Mesmo que essa continuidade não coincida com qualquer ideia de rumo ao progresso - coisa que o jurista claramente abomina -, sua direção, ainda assim, parece muito clara: ela se afasta das imagens de transcendência rumo à afirmação de imagens crescentemente imanentistas. Nada mais contrário ao que Schmitt, e certamente nosso intérprete, consideraria desejável!

A palavra "desejável”, sem dúvida, é de minha lavra, mas não deixa de esclarecer o específico sentido (hermenêutico) de secularização que o livro pretende resgatar. Ao fim e ao cabo, como já foi assinalado, cada época histórica carrega consigo seu sentido hermenêutico peculiar - aliás, é isso que permite distinguir as próprias épocas. Porém, Schmitt e seu intérprete não são de modo algum impassíveis a seus diferentes conteúdos. Ou seja, privilegiar o sentido hermenêutico sobre o histórico é, na verdade, privilegiar um dos possíveis conteúdos do primeiro. E, para todos os efeitos, o senti- 
do que importa como arma de combate teórico é aquele que busca a visibilidade do político, o qual corresponde, em termos históricos, ao período "heroico", porém fugaz, da modernidade nascente, em que o Estado soberano se fez realidade.

Contudo, como tornar esse privilégio justificável a não ser admitindo seu propósito moral? Vale dizer, assumindo a defesa de um valor intrínseco à busca da distinção especificamente política: pois não é precisamente essa distinção que, ao fazer visível o que de outro modo permaneceria oculto, na exata medida em que não está fadada a "ser", ainda assim "deveria ser"? Tal é a essência do combate schmittiano. De certo modo, retomo aqui um desconcerto que, nos tempos da publicação de $O$ conceito do político, o filósofo Leo Strauss havia manifestado, ao contrastar a pretensão, feita no miolo do livro, de dar uma definição própria do político, que nada devesse à moral, e as advertências que o jurista faz na parte final, sobre as consequências negativas - e para quem, senão todas as comunidades humanas? - da rejeição daquele conceito. (A crítica de Leo Strauss pode ser encontrada no apêndice da tradução inglesa de $O$ conceito do político, feita pela Rutgers University Press, 1976.)

Ainda em perspectiva analítica, é também desconcertante acompanhar a tentativa do autor de buscar um equivalente ao propósito da distinção amigo e inimigo numa suposta diferença entre "uma inimizade ilimitada e uma inimizade delimitada” (p. 292), com o político posto a serviço da última. Não há como evitar a conclusão de que essa tentativa é moralmente orientada. Porém, a distinção amigo/inimigo proposta por Schmitt teria de resistir a essa diferença: pois não é ele mesmo que afirma que a distinção só faz sentido se levarmos em conta a intensidade dos conflitos humanos - isto é, seu grau extremo? Como admitir, consistentemente, que possa haver algo que ultrapasse o extremo? Se não faz sentido diferenciar o "extremo" do "mais extremo", só se concebêssemos que "o especificamente político" estivesse, em realidade, aquém do grau extremo...

O outro motivo de desconcerto tem a ver com o debate ideológico no qual o livro se inscreve. Ao longo do texto o autor nunca se distancia da concepção da qual é, em princípio, apenas um intér- prete. Pelo contrário, às invectivas que Schmitt faz contra a corrente que vê como seu adversário central, o "liberalismo", Villas Bôas vai acrescentando, conforme avança para o final, as suas próprias, contra o que considera os herdeiros contemporâneos desse liberalismo (como J. Habermas). Suspeito, porém, que o adversário da visão exposta no livro envolve um leque muito mais amplo de posições ideológicas - eu diria: toda e qualquer posição pluralista, liberal ou não.

A dificuldade de Schmitt com o pluralismo é mais ou menos evidente: refere-se ao fato de que, como vimos, a conjunção de seus conceitos de soberania e do campo do político faz com que o soberano schmittiano detenha o monopólio de decidir "quem é o inimigo". Como primeira aproximação, pode-se precisar, como o faz nosso autor, que esse "inimigo" é apenas um sujeito "externo", isto é, os membros de outra comunidade política que venha a ameaçar a existência da sua. Porém, na medida em que o campo do político é definido pela divisa amigo/inimigo, como qualificar o contestador "interno" do soberano, ou seja, um indivíduo ou grupo adversário que pertença a uma mesma comunidade? A resposta do autor: "Com efeito, o inimigo interno não é o inimigo, mas o criminoso. $\mathrm{O}$ inimigo interno é sinônimo de ameaça interna ou guerra civil, ele não é público, logo, não possui um status" (p. 263). Ou seja, como reconhece Villas Bôas em seguida, todo esforço de evitar atributos normativo-morais negativos ao inimigo externo, qualificando-o exclusivamente pela divisa política, desaparece quando o problema é lidar com o contestador interno da soberania. Desqualificado politicamente, a este resta apenas o direito criminal, além dos atributos morais negativos!

Que esta seria uma resposta tipicamente schmittiana, estou de acordo. Mas, assim como seu intérprete é capaz de expor as fragilidades dos adversários contemporâneos dessa concepção, seria muito proveitoso que ele se dispusesse a problematizar, igualmente, a resposta schmittiana. E nesse caso, ficaria claro que a dificuldade do jurista alemão não é apenas com o liberalismo, mas com esse aspecto central das sociedades democráticas, endossado por uma gama muito variada de doutrinas políticas, liberais e não liberais, que as impede de con- 
ceber uma comunidade política do modo como o soberano schmittiano precisa fazê-lo - isto é, numa forma absolutamente unificada e indiferenciada -, a fim de reivindicar o monopólio da decisão sobre quem é amigo e quem é inimigo.

Minhas perplexidades, reitero, em nada diminuem os méritos de Secularização inacabada. São apenas notas mal-traçadas de um diálogo que, certamente, vai prosseguir. Nossa tarefa foi fornecer ao possível leitor um quadro sintético da obra, dentro do espaço cabível de uma resenha, de modo que é mais do que hora de terminar.

\section{CICERO ARAUJO \\ é professor titular de teoria política no \\ Departamento de Ciência Política da FFLCH/USP. E-mail:craujp@usp.com.br.}

